\title{
EFL teachers' beliefs and performances on code switching (Iranian setting)
}

\author{
Fahime Farjami, Hanieh Davatgari Asl \\ Department of English Language Teaching, Ahar branch, Islamic Azad University, Ahar, Iran
}

\section{Email address:}

fahimefarjami@yahoo.com (F. Farjami), hdavatgar@ymail.com (H. D. Asl)

To cite this article:

Fahime Farjami, Hanieh Davatgari Asl. EFL Teachers' Beliefs and Performances on Code Switching (Iranian Setting). International Journal of Language and Linguistics. Special Issue: Language Teaching and Learning Key Principles (LTLKP).

Vol. 1, No. 4-1, 2013, pp. 6-10. doi: 10.11648/j.ijll.s.20130101.12

\begin{abstract}
Code switching occurs when bilinguals of two or more languages use them in the same discourse. There are different reasons why and several manners how EFL teachers apply this strategy in their classroom setting. Different instructional, cognitive, affective, and behavioral purposes underlies code switching strategy. It can foster different skills and components of language when care and attention is fully given to the tasks. Removing learners' emotional impediments like anxiety, lack of self confidence and weak self esteem in language learning is the outcome of its affective aim. This study was done to find the Iranian teachers' functions, manner, reasons, and contributions of Code-switching in their teaching process. The participants were 20 English teachers from several universities located in North of Iran. They were provided with some interview questions on Code Switching. The analysis of the answers was an indication of similarities and differences in their beliefs and performances on this strategy in their teaching process.
\end{abstract}

Keywords: Code Switching (C.S.), Bilingualism, Culture, Facilitator

\section{Introduction}

The present study is a broad explanation of different aims of applying C.S. by EFL teachers in Iran. In this regard, cognitive and affective functions are analyzed. Also, the functions, reasons, manner etc are elaborated on.

\section{Literature Review}

According to Nunan \& Carter (2001), switching from one language to another in the same discourse is called code switching. In fact, it refers to a transition between the native language of the learners and the foreign language being taught in EFl classroom.

Adendorff (1996) considers C.S. as a communicative resource enabling teachers and students to accomplish a high range of social and educational objectives. (p. 389).

Its modifying effect for personal intentions as a facilitator has been discussed by Trudgil (2000). He believes that Transferring from first language to second language facilitates the acquisition of second language.

As a communication facilitator, Gumperz (1982) finds C.S. beneficial in conveying precise meaning, appealing to the literate and illiterate, capturing attention, stressing a point and communicating more effectively.

There are many reasons why learners use C.S. in their classrooms. Floor holding, equivalence and reiteration are the most common. Floor holding can fill the gap with native language in a target language conversation. Equivalence relates to using equivalents of some lexical items in the target language and accordingly can help learners to improve their linguistic incompetence in target language. Another function of C.S. is reiteration where learners in order to fully convey the message, repeat the target language messages by their native language. Skiba (1997) considers C.S. as a mean for continuity in speech, since it transfers meaning between two languages.

EFL teachers apply C.S. automatically and unconsciously in their classrooms. The use of C.S. by teachers has different functions. Burden (2001) believed that C.S. acts as facilitator in conducting a stress free learning environment, and also helps students to actively participate in classroom activities.

Auer (1995) believed in two types of C.S. The 
participant-related switching which focuses on language preferences and competences of the learners, and the discourse-related switching which focuses on better comprehension or reiteration of an utterance.

Simon (2001) highlighted the point that practicing C.S. in class is related to the task type such as grammatical explanations, cultural information or giving instructions.

As a sociolinguistic phenomenon, the usage and function of C.S. differs in cultures. In this regard, finding about the views and attitudes of EFL teachers toward C.S. sounds interesting and contemplating. Focusing on these points, in the present study, EFL teachers from several universities in North of Iran were provided with the following questions in order to find about functions, manner, reasons, and contributions of C.S.

1) Do you use C.S. in your classes? Why or why not? (Ex. As a learning facilitator, for comprehension purposes, to have a non stressful relaxing environment in classrooms)

2) How do you use C.S.? (Ex. By filling the stop gaps, Translation or word substitution)

3) How Does C.S. relate to learning in EFL classrooms?

\section{Methodology}

\subsection{Participants}

Twenty instructors were randomly selected among five universities in North of Iran including Goldasht University of Applied Science, Islamic Azad University of Chalous, Islamic Azad University of Nowshahr, Islamic Azad University of Tonekabon, Islamic Azad University of Ramsar. The instructors were all Iranian. Two instructors had more than 20 years of teaching experience, six had between 10 to 15 years of experience, and six instructors' experiences were more than 5 years, and the others had less than 5 years of experiences.

\subsection{Data Collection}

The instructors were individually provided with the three above mentioned questions as interview questions by the researcher. In this study, only the information gleaned by 16 out of 20 teachers was emphasized to indicate the findings.

\subsection{Findings}

Participation of Sixteen out of twenty teachers was indicated through several tables.

Table number one indicates the age, gender, years of teaching experience and educational degree of each participant individually.

Table1.Characteristics of the Participants

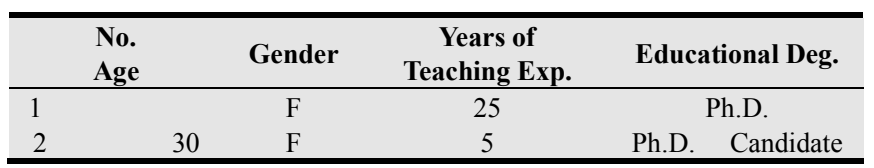

\begin{tabular}{lcccc}
\hline $\begin{array}{c}\text { No. } \\
\text { Age }\end{array}$ & Gender & $\begin{array}{c}\text { Years of } \\
\text { Teaching Exp. }\end{array}$ & Educational Deg. \\
\hline 3 & 34 & F & 10 & M.A. \\
4 & 28 & F & 5 & M.A. \\
5 & 31 & F & 9 & M.A. \\
6 & 40 & F & 10 & Ph.D. \\
7 & 40 & F & 15 & Ph.D. \\
8 & 38 & F & 8 & Ph.D. Candidate \\
9 & 37 & F & 11 & M.A. \\
10 & 29 & F & 8 & M.A. \\
11 & 35 & M & 10 & M.A. \\
12 & 32 & M & 10 & M.A. \\
13 & 26 & M & 4 & M.A. \\
14 & 32 & M & 9 & M.A. \\
15 & 48 & M & 27 & Ph.D. \\
16 & 24 & M & 3 & M.A. \\
\hline
\end{tabular}

As shown in the above table, a number was assigned to each participant to make their answers clear in further steps. The ages of the participants were mostly around 30 and 40 . Their teaching experiences and educational degrees were also pointed. Four teachers were Ph.D. holders in TESOL while others possessed master degree in related scientific domain. Considering the experience of teaching, they were mostly well experienced which indicated that they were scientifically experienced enough to answer the interview questions.

The second table indicates the answer to the first interview question that whether and why teachers use C.S. in their classrooms. As all teachers totally said to use C.S. in their teaching process, the reasons mentioned by any of teachers are shown in front of their numbers in the following table.

Table2. Question no.1: Why do you use C.S. in your classroom?

\begin{tabular}{|c|c|c|c|c|}
\hline \multirow[t]{2}{*}{ No. } & \multicolumn{2}{|c|}{ Learning Facilitator } & \multirow[t]{2}{*}{ Comprehension } & \multirow{2}{*}{$\begin{array}{c}\begin{array}{c}\text { Relaxing } \\
\text { Environment }\end{array} \\
\text { Yes }\end{array}$} \\
\hline & 1 & Yes & & \\
\hline & 2 & Yes & Yes & Yes \\
\hline & 3 & Yes & Yes & Yes \\
\hline & 4 & & Yes & \\
\hline & 5 & Yes & Yes & Yes \\
\hline & 6 & Yes & Yes & \\
\hline & 7 & Yes & Yes & Yes \\
\hline & 8 & Yes & Yes & Yes \\
\hline & 9 & Yes & Yes & \\
\hline & 10 & Yes & Yes & \\
\hline & 11 & & Yes & Yes \\
\hline & 12 & Yes & Yes & Yes \\
\hline & 13 & Yes & Yes & Yes \\
\hline & 14 & Yes & Yes & Yes \\
\hline & 15 & Yes & Yes & Yes \\
\hline & 16 & Yes & Yes & Yes \\
\hline
\end{tabular}

As shown in the above table, all teachers considered C.S. as an accompanying factor in their teaching methods with their own specific underlying rational behind it. Also, the significance of all three reasons in applying C.S. in 
classroom environment was easily recognizable in the table.

The next table is dedicated to show how teachers were willing to use and in fact were using the C.S. in their classrooms.

Table3. Question no.2: How do you use C.S. in your classroom?

\begin{tabular}{cccc}
\hline No. & Filling Stop Gap & Translation & Words Substitution \\
\hline 1 & Yes & Yes \\
2 & & & \\
3 & Yes & Yes & Yes \\
4 & & & \\
5 & Yes & & Yes \\
6 & & Yes & \\
7 & & & Yes \\
8 & Yes & & \\
\hline
\end{tabular}

\begin{tabular}{|c|c|c|c|c|}
\hline No. & & Filling Stop Gap & Translation & Words Substitution \\
\hline & 9 & & Yes & \\
\hline & 10 & & Yes & \\
\hline & 11 & & Yes & \\
\hline & 12 & Yes & & Yes \\
\hline & 13 & & Yes & \\
\hline & 14 & Yes & Yes & \\
\hline & 15 & Yes & & Yes \\
\hline 16 & & Yes & Yes & Yes \\
\hline
\end{tabular}

As visible in the above table, most teachers used more than one form of C.S. as an aid in their teaching process.

Table number four shows a sort of structured elaboration of teachers' attitudes, and contributions toward the advantages of C.S. in learning process.

Table4. Question no.3: How Does C.S. relate to learning in EFL classrooms?

\begin{tabular}{|c|c|}
\hline No & Participants' Answers \\
\hline 1 & It helps the learners to refocus after a short pause. \\
\hline 2 & It helps the learners to understand what they are learning or reading. \\
\hline 3 & It gives learners feeling of comfort while learning without fear of making mistakes. \\
\hline 4 & It acts as a sort of helping process in learning. \\
\hline 5 & It facilitates learning via getting learners actively involved when they hear new words. \\
\hline 6 & It fosters the process of learning by introducing new subjects in both languages. \\
\hline 7 & It is of great help in teaching content-based materials. It also increases the learners' understanding. \\
\hline 8 & It helps clarifying instructions, and improving the class environment. \\
\hline 9 & It can act as a facilitator, but if regularly used, may cause learners to expect teacher to do it all the time. \\
\hline 10 & It makes learners more conscious about what they learn. Accordingly, It makes the learning process faster, easier, more effective and durable. \\
\hline 11 & In the case of using C.S. learners must be encouraged to use target language especially in writing tasks. \\
\hline 12 & By C.S. learners can switch when they don't know the meaning of some words, however it all refers to the subject of lesson. \\
\hline 13 & If frequently used in classrooms, it slacks the learners' ability to put the language in to practice. \\
\hline 14 & In the case of comprehensibility and intimacy, the role of C.S. is obvious and undeniable. \\
\hline 15 & It acts as a link between teacher and learner depending on how much and how often it is used. \\
\hline 16 & It is time saving and also develops the sociolinguistic and strategic competences of the learners. \\
\hline
\end{tabular}

As numbered in the above table, any individual teacher had his own special attitude toward the effect of using C.S. on learning process in EFL classrooms.

To elaborate on the above tables, the answer to all questions by each individual teacher was explained in details. Teacher number one with twenty five years of experience, used stop gaps and substitution especially while intending to tell a joke in Farsi to make a jovial and hilarious condition, and she believed that C.S. could relieve learners momentarily. She also considered the C.S. as a method removing the negative affective factors like anxiety and lack of self confidence. Moreover, she pointed the role of C.S. in establishing emotional relations with the learners that could be possible through increasing the learners' satisfaction and positive atmosphere in class.

The second thirty year old teacher used C.S. to check the comprehensibility of the learners over the subject, and also to reduce class pressure. She focused on the point that the empty face of the learners was a signal showing no intake on the side of the learners encountering many new words. Her first selection to fade that away, was paraphrasing the sentences in English, giving examples of daily life affair, and just in the case of no use, he switched in to Farsi.

While the third teacher expressed that she used C.S. to start happiness and laughter in the class, the fourth twenty eight year old teacher with ten years of experience desired to use C.S. when applying the abstract terms in order to avoid the learners loose the stream of the lecture. She used it just in the case of assuring that learners didn't understand the meaning in English. In addition, she believed that using much of C.S. in class may lead to a sort of bilingual class which is a definite harm to learning a foreign language. 
Drawing the attention of the learners, getting learners involved in the class discussions were some other reasons teacher number five mentioned in the interview. He at first pointed out that sometimes he used C.S. unintentionally, for the stopgaps may not have any equivalent in English Language. She emphasized that there are also some sounds specific to Iranian cultures for which no English words are found, so she had to resort to C.S. to remove the gap between the phonetic system of Farsi and English language.

The sixth teacher, Ph.D. holder with ten years of experience, said to use C.S. in class by chance. She considered the fostering role of C.S. in learning process when the teacher systematically applied C.S. in teaching procedures. More importantly, she stressed the consciousness and awareness of the learning process, and mentioned the consciousness raising potential of C.S. in this regard which surely led to the learners' critical language awareness.

Teacher number seven with fifteen years of experience strongly believed in the use of C.S. by re-explaining in Farsi in the form of paragraphs, because he insisted on teaching through content based method, as it leads learners to understand the information better.

Number eight was a female teacher with eight years of experience who emphasized on establishing a close rapport between learner and teacher through using C.S. in the class. In this regard, she highly respected the learners' cultures. In addition, she said that it is useful to respond in the students Farsi language when you overhear them talking to each other which lets them know you are listening, occasionally to clarify instructions. She also believed in the positive role that C.S. can play a crucial role in acknowledgement and appreciation of learners' ethnic diversity and individual differences.

Teacher number nine was a thirty seven year old lady who used C.S. in the form of translation to avoid long complicated definitions and explanations. However, she believed in the conservative use of C.S. to stop the learners from getting used to hearing the Farsi language in classroom.

A twenty nine year old female with eight years of experience was the tenth teacher who hated to use C.S., but unfortunately she had to use it to check if learners understood the grammatical structures and newly presented vocabularies. As she said, it happened that sometimes the learners did not know some grammatical structures in their own language. They didn't know the rules, the ways of formation, so it was impossible to teach something with knowing that learners understood it in their native language. Besides, she highly took the language image of the learners in to account, and said that they should know the exact equivalents in Farsi language.

Teacher number eleven reminded that most of the learners were commonly looking for Farsi explanations to get the meaning properly. Having highlighted the relaxing impact of C.S. in class environment, this male teacher with ten years of teaching experience debated on encouraging the learners to use Farsi language while doing writing tasks to enjoy their time.

Teacher number twelve mentioned that he used C.S. to get the learners involved in class activities, to interact with the learners while meeting their needs. He meanwhile emphasized on the use of C.S. when submitting certain grammatical points and syntactic boundaries.

A young male teacher (number thirteen) with four years of experience was interested in the use of C.S. as it had a significant influence on consolidating newly taught grammar points and also vocabularies. He believed feeling the teacher's interest toward native language by the learners inspired them to respect the English language. Accordingly, their engagement in doing assigned tasks was increased by C.S. But, he considered some direct translations to be erroneous for which the solution was to know about different usage. Moreover, he warned all teachers that excessive application of C.S. not only was productive, but also was counter-productive leading the learners to be spoon fed and sluggish in English language production.

Teacher number Fourteen with nine years of experience mentioned the intimacy and relaxing effect of using C.S. in classroom. He stressed that the learners must be provided with appropriate input related to their background knowledge in order to remove affective barriers such as insecurity, and also to have an effective learning.

A forty eight male teacher (number fifteen) with around thirty years of experience mentioned a lot of profits of using C.S. in classroom such as to express his feelings about what might go on in class, to add the learners' understanding of the materials delivered, to avoid misunderstanding, to have reinforcement and back up over what was taught, to save the time, and also to draw the learners' attention. He strongly insisted on using C.S. in classroom to make a long lasting emotional link between the teacher and the learner.

The last participant was a young 24 year old male who said to use Farsi language in his classes. He found C.S. time saving as the English explanations could be very long lasting. He also highlighted that the use of C.S. in teaching difficult words was highly beneficial, and its impact on the development of the learners' sociolinguistic and strategic competences while doing translation was undeniable.

\section{Conclusion}

Nearly all the teachers at several Universities in North of Iran regarded the C.S. as a mean to facilitate language learning, to make a more relaxing learning environment, since learners seemed to feel more comfortable while facing familiar words in native language within the English language context. Inclusion of C.S. in teaching process diminishes affective filter by removing anxiety, since stress hinders the beneficial interaction in teaching classes. C.S. provides the feeling of familiarity which promotes the learners' motivation. Some teachers stated that they make a joke more understandable via C.S. to have a hilarious 
environment in the classroom. C.S. can also act as a warm up tool as well as a facilitator to overcome the possible ambiguities.

Some of the participants highlighted that C.S. should not be used for all the instructional activities. Other teachers focused on the facilitative effect of C.S. in learning vocabularies.

Moreover, in teaching content based materials, C.S. causes progress considering the objectives of teaching. In accordance, some teachers claimed that C.S. helped them to make the content more comprehensible. They also marked translation to make a clarified form of figures of speech. Teaching content has a crucial role in translation classes, as the learners are supposed to have the necessary knowledge of foreign language; since they all have passed the university entrance exam, and are considered as at least intermediate command level of English. As English language learning requires to be practiced fluently, teachers may not confirm the regular use of C.S. whereas they sometimes use it make the instructions clear. These examples indicated the broad use of considering the course objectives.

As a conclusion, all teachers somehow benefit the functions of C.S. in a sense. However its function and frequency depend on their course objectives. Teachers mostly believed in C.S. as a facilitator, because it helps learners perceive the instructions and meanings of new vocabularies, and also increases the learners' involvement in the learning process within a non stressful environment. Accordingly C.S. provides a sort of familiarity which creates relief feeling inside the learners.

Clarifying the complex grammatical points, vocabulary items and removing the negative feelings of anxiety, de motivation, in security are more merits of C.S. Moreover, the pacifying relaxing impact of using Farsi language in classrooms was strongly emphasized by the participants. Additionally, there was a focus on providing the learners with comprehensible input appropriate to their level of knowledge and information.

\section{References}

[1] Adendorff, R. (1996). The functions of code-switching among high school teachers and students in KwaZulu and implications for teacher education. In K. M. Bailey \& D. Nunan (Eds.). Voices from classroom: Qualitative research in second language learning (pp. 388-406). Cambridge: Cambridge University Press.

[2] Auer, P. (1995). The pragmatics of code-switching: A sequential approach. In L. Milroy, \& P. Muysken (Eds.), One speaker, two languages: Cross-disciplinary perspectives on code-switching (pp. 115-135). Cambridge: Cambridge University Press.

[3] Burden, P. (2001). When do native English speakers and Japanese college students disagree about the use of Japanese in the English conversation classroom? The Language Teacher, April 2001. Retrieved from http://www.jaltpublications.org/ttt/articles/2001/04/burden

[4] Gumperz, J. J. (1982). Discourse strategies. Cambridge: Cambridge University Press. http://dx.doi.org/10.1017/CBO9780511611834

[5] Numan, D., \& Carter, D. (2001). Teaching English to speakers of other languages. Cambridge: Cambridge University Press.

[6] Simon, D.-L. (2001). Towards a new understanding of codeswitching in the foreign language classroom. In R. Jacobson (Ed.) Codeswitching Worldwide II, pp. 311-342. Berlin: Mouton de Gruyter.

[7] Skiba, R. (1997). Code Switching as a Countenance of Language Interference. The Internet

[8] TESL Journal 3, 10. Retrieved 7th February 2007 from http://iteslj.org/Articles/Skiba-CodeSwitching.html

[9] Trudgill, P. 2000, 4th ed. Sociolinguistics. London: Penguin. 